\title{
Preschool Children's Foreign Language Vocabulary Learning by Embodying Words Through Physical Activity and Gesturing
}

\author{
Konstantina Toumpaniari ${ }^{1}$ - Sofie Loyens ${ }^{1,2}$. \\ Myrto-Foteini Mavilidi ${ }^{1,3} \cdot$ Fred Paas ${ }^{1,3}$
}

Published online: 16 June 2015

C The Author(s) 2015. This article is published with open access at Springerlink.com

\begin{abstract}
Research has demonstrated that physical activity involving gross motor activities can lead to better cognitive functioning and higher academic achievement scores. In addition, research within the theoretical framework of embodied cognition has shown that embodying knowledge through the use of more subtle motor activities, such as task-relevant gestures, has a positive effect on learning. In this study, we investigated whether combining both physical activities and gestures could improve learning even more in a 4-week intervention program on foreign language vocabulary learning in preschool children. The main hypothesis that learning by embodying words through task-relevant enactment gestures and physical activities would be perceived as the preferred teaching method and lead to higher learning outcomes than learning by embodying words through task-relevant enactment gestures only, and learning without physical activities or gestures was confirmed by the results. The results of this study hold great promise for instructional methods combining physical activities and gestures as enhancers of children's learning.
\end{abstract}

Keywords Learning $\cdot$ Physical activity $\cdot$ Gesturing $\cdot$ Embodied cognition $\cdot$ Preschool children

Since the ancient times, physical activity has been linked with a healthy mind, and physical exercise has been a vital part of education. The phrase "Mens sana in corpore sano" (a sound mind in a healthy body) coming from the Roman poet Juvenal (Apr. 55-135 AD) underlines the

Myrto-Foteini Mavilidi

mfm351@uowmail.edu.au

Sofie Loyens

s.loyens@ucr.nl

Fred Paas

paas@fsw.eur.nl

1 Institute of Psychology, Erasmus University Rotterdam, P.O. Box 1738, 3000 DR Rotterdam, The Netherlands

2 University College Roosevelt, P.O. Box 94, 4330 AB Middelburg, The Netherlands

3 Early Start Research Institute, University of Wollongong, Wollongong, NSW 2522, Australia 
importance that people gave to a healthy body as they thought it was inextricably linked to a healthy mind. Nowadays, science has come to prove that even a little exercise before a course or a job can enhance memory and help us perform better (e.g., Strong et al. 2005).

Numerous intervention studies have shown the positive acute and chronic effects of exercise on cognitive functioning in children, adolescents, young, and old adults (for reviews, see Fedewa and Ahn 2011; Sibley and Etnier 2003; Tomporowski et al. 2008). According to Sibley and Etnier (2003), there is a significant positive relationship between physical activity and cognitive function or academic achievementcita in school-aged children. More specifically, school-aged children who are more active score better on perceptual skills, IQ, academic achievement, verbal tests, math tests, and developmental level/academic readiness than less active children. Hillman et al. (2005) examined the relationship between age, aerobic fitness, and cognitive function in low- and high-fit preadolescent children and found that aerobic fitness was positively related with the neuroelectric function of attention, working memory, and response speed in preadolescent children engaged in a stimulus discrimination task.

There are many ways one can incorporate physical activity into the school schedule. For instance, it has been found that a classroom-based physical activity program, such as the "Energizers," can be effective for increasing daily in-school physical activity and enhancing on-task behavior during instruction time (Mahar et al. 2006). Energizers is a program that contains short classroom-based physical activities that last approximately $10 \mathrm{~min}$, involves no equipment, incorporates grade-appropriate learning materials, and requires little-to-no-teacher preparation. For instance, one activity from the Energizers program involves the teacher reading aloud a text containing action verbs and the students acting like the verbs (e.g., "jump," "walk," "dive," etc.). Mahar et al. (2006) conducted a study using this classroombased physical activity program in order to assess its effects on elementary children's in-school physical activity levels during the school day and on-task behavior during academic instruction time. The results showed that the students who took part in the Energizers activities were more active and energetic during the school day and showed better on-task behavior than the ones who did not receive the Energizers intervention activities.

In addition, in their review, Tomporowski et. al (2008) concluded that the results from research conducted over the past few years suggest that the positive effects of exercise training on children's mental functioning are mainly found in tasks that involve executive functions (i.e., processes required to select, organize, and properly initiate goal-directed actions). Tomporowski et al. concluded that despite the fact that there are still several unanswered questions regarding the relation between exercise and children's cognitive functioning, exercise programs are important methods for improving aspects of children's mental functioning that are central to cognitive and social development as well as to facing both academic and lifespan challenges.

According to Pontifex et al. (2009), aerobic exercise of moderate intensity has also been proven to cause general improvements in cognitive performance, in comparison to resistance exercise or seated rest, with larger improvements found under highly demanding conditions in terms of working memory capacity.

Although academic performance has been found to improve with physical activity, physical activity tends to decline across childhood, with the greatest declines during elementary school (e.g., Kim and Lee 2009). As a reaction to this phenomenon, physically active academic courses such as Texas I-CAN! (Initiatives for Children's Activity and Nutrition; Bartholomew and Jowers 2011) have been developed. These courses aim at increasing physical activity while at the same time addressing educational goals. According to Bartholomew and Jowers 
(2011), such active academic lessons can be used as an approach to school-based boosts of physical activity in a fun and cost-effective way. One example of Texas I-CAN! program is called Spelling Freeze Tag. In this course, children are released to run within an outdoor area marked off by cones and when tagged they "freeze" in place with their hands raised. Then, another student with a list of spelling words quizzes one of the students who are "frozen." If answered correctly, the student is then released to continue with the running and try to avoid being tagged again. If not, a second word is presented and so on. This course is thus used for reviewing factual information.

Donnelly and Lambourne (2011) examined the Physical Activity Across the Curriculum (PAAC) intervention that consists of moderate to vigorous physically active academic lessons. PAAC can be applied to various academic areas such as math, language, spelling, geography, history, science, and health. In addition, PAAC promotes the idea that physical activity can occur at any place, any time. As an example of a PAAC lesson, a geography lesson can consist of having children run to the area defined appropriately for one of the four directions (north, south, east, and west). Then, if, for instance, Canada is called, the students would have to run to the north space. Donnelly and Lambourne (2011) concluded that implementing physical activity interventions in the classroom is a way to increase physical activity. Increased physical activity has the potential to positively affect academic performance through improved fitness and fatness (see also, Davis and Cooper 2011).

Kibbe et al. (2011) investigated the effect of the TAKE 10! classroom-based physical activity program (see http://www.take10.net/2 in elementary schools. This program integrates movement and learning by engaging students in physical activity, while at the same time strengthening specific learning objectives in math, reading, science, social studies, language arts, and general health. Kibbe et al. (2011) showed that teachers were willing to implement TAKE 10 ! in the classroom while at the same time the students benefited by experiencing higher physical activity levels as well as higher scores in math, reading, and spelling.

Whereas these classroom-based interventions targeting physical activity and academic performance goals have provided promising results, more well-controlled research is needed to be able to provide conclusive evidence for their positive effects on children's cognitive performance and health. Interestingly, not only gross movements involved in physical activity can enhance cognitive performance but also more subtle movements such as gestures. Recent research findings support the embodied character of learning, suggesting that learning is a cognitive process which is inextricably linked to the body's interactions with the world (Wilson 2002; see also Pouw et al. 2014; Pouw et al. 2014). Embodiment facilitates cognitive processes related to learning, such as conceptual development and comprehension (Lindgren and Johnson-Glenberg 2013). Positive effects of embodied learning (i.e., cognition builds on the interaction of the human body with its physical environment; Wilson 2002) have been found in multiple research areas, such as cognitive psychology, social psychology, linguistics, gesture, and mathematics (Lindgren and Johnson-Glenberg 2013).

Recent studies demonstrate that learning activities that involve high levels of embodiment result in a greater chance of retrieval and retention (Lindgren and Johnson-Glenberg 2013). The construction of richer mental representations by the additional cues that bodily movements provide to memory, and the associated reduction of cognitive load have been proposed as possible explanations for the effects of embodiment (e.g., Goldin-Meadow et al. 2001; Paas and Sweller 2012).

According to Hostetter and Alibali (2008), body movements such as gestures can facilitate the retrieval of mental lexical items. Review studies have shown that gesturing has a 
fundamental impact on a range of educationally relevant cognitive functions (see GoldinMeadow et al. 2001; Hostetter 2011). In addition, research has shown that enactment, which is the phenomenon of acting something (e.g., phrases) out, is effective for learning. Recall of enacted action phrases has been found to be superior to recall of action phrases without enactment (Cohen and Otterbein 1992; Engelkamp and Cohen 1991). Engelkamp and Zimmer $(1984,1985)$ have demonstrated that the free recall of enacted sentences is superior to the recall of spoken sentences and to the recall of visually imaged sentences, indicating that the enactment effect is not a mere visual effect. Engelkamp and Zimmer (1985) explain the enactment effect on memorization by postulating that the encoding of enacted events involves a verbal modality, a visual modality, and a motor modality.

The present study is unique in the sense that it focused on the combination of classroombased enactment gestures and physical activities to facilitate learning. The main purpose of this study was to examine whether preschool children's learning of a foreign language vocabulary by embodying words through task-relevant enactment gestures and physical activities would be perceived as the preferred teaching method and lead to higher learning outcomes than learning by embodying words through task-relevant enactment gestures only and learning in a conventional way without gestures and physical activities.

It was assumed that children would benefit from the combination of physical activity and gesturing in three ways. Firstly, through cognitive gains due to the positive effects of enactment on learning, as enactment has been found to add something to the memory trace of the event as well as make the trace richer, or more distinctive and consequently easier to find at recall (Cohen and Otterbein 1992; Engelkamp and Cohen 1991). Secondly, through physiological processes due to the fact that physical activity has been proven to have a positive effect on executive functions, possibly because of an increased cerebral blood flow and oxygenation and increased efficiency of neuronal processes (Hillman et al. 2005; Pontifex et al. 2009). Thirdly, through positive affective effects, because the children will acquire knowledge in a fun and playful way, something that will give them a head start for primary school as well as for education in general, as they will be more positively motivated towards learning (Sibley et al., 2003).

Three experimental conditions were created to investigate whether learning a foreign language vocabulary by embodying words through gestures or through gestures and physical activities is more effective than learning in a conventional way without gestures and physical activities and whether learning a foreign language vocabulary by embodying words through task-relevant gestures and physical activities is more effective for learning than by embodying words through gestures only. In the first experimental condition (embodying words through gesturing), the children had to make enactment gestures while learning about animal names in a foreign language. In the second experimental condition (embodying words through physical activity and gesturing), enactment gestures were integrated with enactment physical activities, in such a way that the physical activities were relevant to the foreign language animal words to be learned. In a third control condition (control), children were taught in the conventional way, in which the teacher simply presented the learning materials, and neither gestures nor physical activities were involved.

Based on the cognitive, physiological, and affective effects found in previous research on the effects of physical activity and gesturing on academic performance, it was hypothesized that the condition in which words were embodied through task-relevant physical activity and gesturing and the condition in which words were embodied through task-relevant gesturing would lead to better learning outcomes than the control condition (hypothesis 1). In addition, it was hypothesized that the condition in which words were embodied through task-relevant 
physical activities and gestures would lead to better learning outcomes than the condition in which the words were embodied through gestures (hypothesis 2). Finally, based on the affective effects of the different teaching methods, it was hypothesized that children in the condition in which words were embodied through physical activity and gesturing would provide higher scores for how much they liked the teaching method and for whether they would like to be taught with this method in the future than the children in the condition in which the words were embodied through gestures and the children in the control condition (hypothesis 3).

\section{Method}

\section{Participants}

Participants were 67 kindergarten 4-year-old students (30 boys and 37 girls), in three classes, from two kindergartens in Athens. Before the experiment, both teachers and parents were informed by the school principals about the general procedure, and permission was asked from the parents via e-mail or in person (for the ones that did not have an e-mail address). In the email or in person, the whole procedure was explained in detail. All of the parents agreed and some of them gave their contact details in order for the final results to be sent to them after the experiment. The total duration of the experiment was 4 weeks. Because it was not feasible to randomize the participants, the three classes were randomly assigned to one of the three conditions of the study before the start of the experiment. Twenty-three children were allocated to the embodying words through physical activity and gesturing condition, 23 children to the embodying words through gesturing condition, and 21 children to the control condition.

\section{Materials and Procedure}

For this study, no extra preparation time or special equipment was needed for the teachers and participants. Teaching was done by the experimenter and took place in the children's classrooms. The teachers' role was solely supportive, in case children did not pay attention during class. Participants were taught 20 new words in a foreign language (i.e., English), all falling in the category of animal names. Flashcards were used to teach the words by demonstrating the respective animal in a picture while at the same time saying its name first in Greek and then in

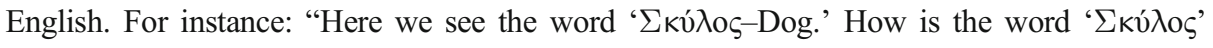
called in English? Dog." The flashcards were obtained from the following websites, namely http://www.mrprintables.com/ and http://www.havefunteaching.com/. Regarding the two experimental conditions (embodying words through physical activity and gesturing and embodying words through gesturing), physical activities such as the ones described in the "K-2 Energizers" program were used (Mahar et al. 2006; Mahar 2011; see http://www.ecu. edu/cs-hhp/exss/apl.cfm). More specifically, in the embodying words through physical activity and gesturing condition activities, children acted out movements from various animals (e.g., pig, cow, horse, sheep, and dog). In the embodying words through gesturing condition, children acted out movements of the same animals with gestures without moving from their position. Examples of the specific activities conducted in each condition are explained below.

Every week, each class was taught the list of 20 animal words in English (see Appendix 1). In each session, the same list of 20 words was taught. Classes lasted $1 \mathrm{~h}$ per day, two sessions 
per week in each condition for a 4-week period, with a total of $8 \mathrm{~h}$ learning of the foreign language words. Hence, every week, a total of $6 \mathrm{~h}$ was taught for all three groups, resulting in a sum of $24 \mathrm{~h}$ in total for all three groups during the 4-week period.

In all three conditions, the experimenter-teacher started by calling out an animal name while showing it with a flash card and the children tried to find out how this animal was called in English. When it was clear that no one knew the English name, the experimenter called out

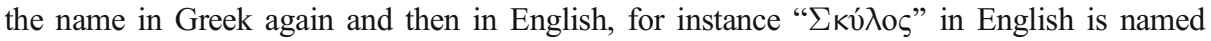
"Dog." After that, the condition-specific activities started and the whole procedure was repeated until the end of the 1-h lesson was reached.

The condition-specific activity in the control condition was that the children repeated the name of the animal in both languages. No movements or gestures were involved in this condition. In the embodying words through physical activity and gesturing, the children repeated the name in both languages and were instructed to imitate the movements of each animal until a new animal was called out. For instance, when the experimenter would call the pair word $\Sigma \kappa u ́ \lambda o \varsigma$-Dog, the children would repeat it and then the experimenter said "let' s make gestures and move, walk or roll over like dogs." Then, the children would firstly pose like dogs normally do and then started walking and generally moving like dogs. The teaching process in this condition was based on the "On the farm" activity of the Energizers classroombased program (Mahar et al. 2006). In the embodying words through gesturing condition, the children repeated the name in both languages and were instructed to use gestures to show the way the animal moves, but without physical activity. For instance, in the dog example, the

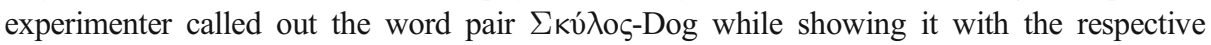
flashcard and then the children were instructed to just act like a dog, but without moving from their place, and whoever tended to move was verbally corrected by the experimenter. In the dog example, this was expressed in the following way: "Now, I want every one of you to pose, stand or sit like dogs usually do. Be careful, we do not move from our place at all. Whoever walks, jumps or moves in any other way, loses." The teaching process in this condition was based on the "It's a Zoo in here" activity of the Energizers classroom-based program (Mahar et al. 2006).

The whole teaching procedure lasted 4 weeks in total. At the end of the fourth week, an individual post-test was administered to all children of each group, which consisted of two parts. In the first part of the post-test, children were asked to evaluate the teaching method by answering two questions on a five-point Likert-type rating scale using both verbal labels and smileys (Jäger and Bortz 2001). The smiley scale was used in two studies with 239 adult participants. Results revealed that the scale was reliable and was not influenced by age, gender, or education (Jäger and Bortz 2001). For the first question, "Did you like the course?", the verbal labels ranged from 1 "Did not like it at all" to 5 "Liked it a lot." For the second question, "Would you like to be taught this way in the future?", the verbal labels ranged from 1 "Not at all" to 5 "I would love to." The questions and the labels were read out by the researchers and children had to indicate their answers on the smiley scale. A coefficient of internal consistency (Cronbach's coefficient alpha) of .69 was obtained with the smiley scale in this study.

In the second part of the post-test, the children were individually tested to determine how many words they could remember. The test was administered in a cued-recall format, which in this case consisted of the experimenter saying the animal word in Greek and the child saying the same animal word in English. The words were checked with a checklist containing all the words that were taught. The experimenter ticked the "yes" checkbox when a word was correctly recalled and the "no" checkbox when a word was not correctly recalled. 


\section{Research Design}

In a quasi-experimental study, three levels of the independent variable type of embodiment (embodying words through physical activity and gesturing, embodying words through gesturing, and control) were compared in a between subjects design. Because practically it was not possible to randomly assign children to conditions, the three classes were randomly assigned to the three conditions.

Dependent variables were the performance on the total number of words that children could remember (number of recalled words) after the 4-week intervention reflecting the knowledge they had obtained and the mean scores of the evaluation of the instructional methods (i.e., how much they liked the instruction they received; evaluation).

\section{Statistical Analysis}

One-way analyses of variance (ANOVA) were performed to determine the main effects of the independent variable instructional condition, and directional independent $t$ tests were performed to determine the specific hypothesized differences between instructional conditions.

\section{Results}

Before the ANOVAs were conducted, a Shapiro-Wilk $W$ test was conducted, $p=0.64$, which indicated that the data were normally distributed. Means and standard deviations per condition are provided in Table 1. $P$ values $<.05$ were considered significant and Eta-squared $\eta^{2}$ was used as an estimate of effect size, with $\eta^{2}=.02$ corresponding to a small effect, $\eta^{2}=.13$ corresponding to a moderate effect, and $\eta^{2}=.26$ corresponding to a large effect (Cohen 1988, 2013).

The one-way ANOVA for test performance revealed a statistically significant difference among the three experimental conditions, $F(2,64)=8.847, p<.001$, $\eta^{2}=.22$, indicating a moderate to large effect size. Directional $t$ tests revealed that both embodying words either through gestures and through both physical activity and gestures resulted in higher test performance than learning the words in the conventional way without gestures and physical activities, $t(64)=2.77, p<.001$ (one-tailed). In addition, embodying words through task-relevant physical activities and gestures resulted in higher total test performance than embodying words through gestures, $t(64)=3.17, p<.001$.

Table 1 Means and standard deviations of recalled words and instructional method evaluation as a function of instructional condition

\begin{tabular}{llllll}
\hline & \multicolumn{2}{c}{ Recalled words } & & \multicolumn{2}{c}{ Course evaluation } \\
\cline { 2 - 3 } & $\mathrm{M}$ & $\mathrm{SD}$ & & $\mathrm{M}$ & $\mathrm{SD}$ \\
\hline Control & 14.62 & 2.31 & & 3.78 & .49 \\
Gesturing & 15.13 & 2.01 & & 3.87 & .41 \\
Physical activity and gesturing & 16.96 & 1.49 & & 4.17 & .44 \\
\hline
\end{tabular}


The ANOVA for the instruction evaluation, which was performed on the combined scores on the questions, "Did you like the course?" and "Would you like to be taught this way in the future?", revealed a significant difference among the three conditions, $F(2,64)=4.708, p=.012, \eta^{2}=.13$, indicating a moderate effect size. Directional $t$ tests revealed that children evaluated both the embodying words through physical activity and gesturing condition and the embodying words through gesturing condition more positive than the conventional teaching method, $t(64)=2.01, p<.001$. In addition, it was found that children preferred the condition in which words were embodied through physical activity and gestures over the condition in which only gestures were used, $t(64)=2.317, p<.001$.

\section{Conclusions and Discussion}

The present study examined how gesturing and physical activity can influence learning when learning foreign language words at a very young age. Hypothesis 1, which stated that the conditions in which words were either embodied through gestures only or through gestures and physical activity would be more beneficial for learning than a conventional way of teaching without gestures and physical activities, was confirmed by the results. These results are in line with previous research, indicating that classroom-based physical activity programs, such as the Energizers, are beneficial for learning such as improved on-task behavior (Tomporowski et al. 2008), better memory function, and reaction time (Hillman et al. 2005; Tomporowski et al. 2008). In addition, hypothesis 2, which stated that embodying words through task-relevant physical activities and gestures would be more efficient for the learning of foreign language words than embodying words through gestures, was confirmed. In line with hypothesis 3 , the results revealed that the children liked the condition in which words were embodied through physical activity and gesturing the most as a teaching method and would choose that as their preferred way to be taught in the future. Because the evaluation of the teaching method was based on self-reported data and the two questions ("Did you like the course?" and "Would you like to be taught this way in the future?") were explanatory and linked to each other, the aggregated scores on both questions were used in order to better reflect the higher-order concept of children's perception about the teaching method.

The results of the present study are in line with previous findings regarding the interaction between physical activity and learning. As mentioned in the introduction, physical activity not only leads to better academic achievement but also sets the roots for healthy habits for the children, something crucial in our era where sedentariness has become a daily routine for many children. For this reason, we agree with Sibley and Etnier (2003) that physical activity must become an inextricable part of children's school days. Furthermore, the present study demonstrated that combining physical activities with task-relevant gestures lead to even better learning performances in terms of cued recall. As mentioned in the introduction, by combining physical activity with task-relevant gestures, learners can benefit from both the cognitive as well as the physiological gains. On top of these benefits, children prefer being active and making gestures in the classroom.

An alternative explanation of the present results is that the children might have been more enthusiastic about the new active teaching methods. Consequently, they might not only have 
spent more physical effort but also might have been willing to invest more mental effort in learning. Although it seems unlikely that this was the only reason for the higher learning outcomes because task-relevant physical activity plus gestures led to higher learning outcomes than gestures only, the children's enthusiasm about the teaching method might still explain part of the learning results. Therefore, it is important for future research to include a control condition in which children are presented with a new teaching method, but do not have to gesture, physically active, or both.

One limitation of the present study is the randomization procedure. More specifically, in our study, while the classes were randomly assigned to the experimental conditions, the students could not be randomly assigned to the conditions; this is a consequence of conducting research in a practical setting with children of a very young age.

Another limitation was the fact that no measure of fitness, for example through the use of pedometers, was used in the present study, which makes it impossible to infer the children's improvement in terms of fitness (Lubans et al. 2009). Future research is recommended to use these measures to provide a better perspective of children's physical improvement.

Furthermore, another issue was that only one specific type of task (i.e., learning foreign language vocabulary) and one specific type of memory test (i.e., immediate cued recall) were used. Future research needs to shed light on the effects of embodied physical activities on a variety of tasks (e.g., math and science) and tests (e.g., free recall) in order to see whether the effects can be generalized to other tasks. In addition, it would be interesting to investigate the long-term effects on retention with delayed tests.

The duration of the current study was rather long (4 weeks), but it could be argued that it was too short to determine the long-term effects of embodied physical activities on children's learning. Future research should explore the effects of embodied physical activities in longer, preferably longitudinal studies.

Although it proved to be easy to implement physical activities in the classroom of young children, it could be more difficult for older children and adolescents. Acting out animal movements with physical activities and gestures can be considered an easy task. It is clear that it would be difficult to use the current learning strategies based on physical activities and gestures for words representing more abstract and general concepts, such as air and spirit, that older children have to deal with. In addition, with older children, it might be more difficult for teachers to keep order in the classroom when integrating physical activity in the classroom. Future research is recommended to examine the effects of embodied physical activities for different types of words and throughout the school years.

Summing up, regardless of its limitations, the present study has added to the already existing literature that physical activity can lead to better learning results. The new insight that this study has offered is that the positive effects of physical activity or embodied activities can become more pronounced when physical activities are embodied. The present study also supports the view that physically active school programs such as the Energizers can prove to be a useful asset for teachers even when teaching a new material at a very young age. Embodying physical activities in the classroom holds great promise as a way to improve physical health as well as enhance children's learning. 


\section{Appendix 1}

Post-Test Part.

Name:

Yes - No

1. Гoupoúvı-Pig

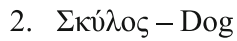

3. $\Gamma \alpha ́ \tau \alpha-C a t$

4. $\mathrm{A} \gamma \varepsilon \lambda \alpha \dot{\alpha} \delta \alpha-\mathrm{Cow}$

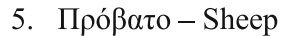

6. Nv $\chi \tau \varepsilon \rho i ́ \delta \alpha-B a t$

7. Аркои́ $\alpha$ - Bear

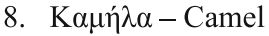

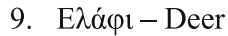

10. $\Delta \varepsilon \lambda$ pívr - Dolphin

11. E $\lambda \dot{\varepsilon} \varphi \alpha v \tau \alpha \varsigma$ - Elephant

12. A $A \varepsilon \varepsilon \pi \mathrm{ov}-$ Fox

13. K $\alpha \mu \eta \lambda o \pi \alpha ́ \rho \delta \alpha \lambda \eta-$ Giraffe

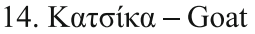

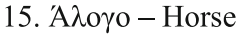

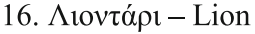

17. Maïnov́ - Monkey

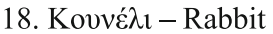

19. Tí $\rho \rho \eta$ - Tiger

20. Zé $\beta \rho \alpha-Z e b r a$

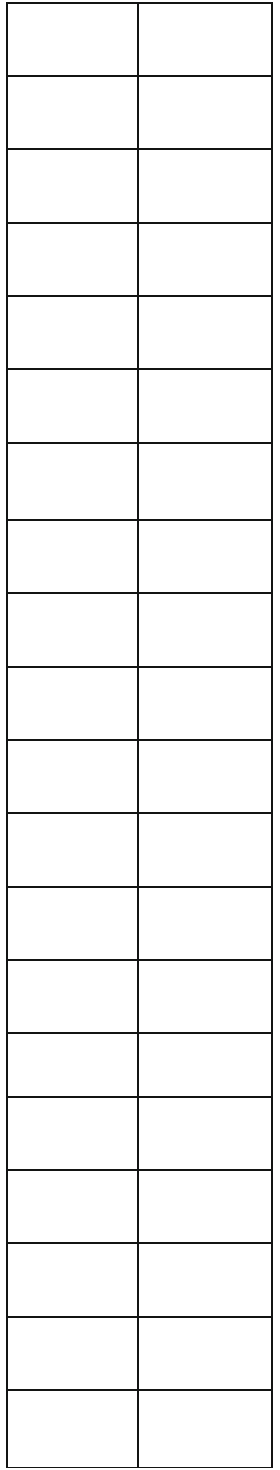


Open Access This article is distributed under the terms of the Creative Commons Attribution 4.0 International License (http://creativecommons.org/licenses/by/4.0/), which permits unrestricted use, distribution, and reproduction in any medium, provided you give appropriate credit to the original author(s) and the source, provide a link to the Creative Commons license, and indicate if changes were made.

\section{References}

Bartholomew, J. B., \& Jowers, E. M. (2011). Physically active academic lessons in elementary children. Preventive Medicine, 52, S51-S54.

\section{Chicago.}

Cohen, J. (1988). Statistical power analysis for the behavioral sciences (2nd ed.). Hillsdale: Erlbaum.

Cohen, J. (2013). Statistical power analysis for the behavioral sciences. Routledge Academic.

Cohen, R. L., \& Otterbein, N. (1992). The mnemonic effect of speech gestures: pantomimic and non-pantomimic gestures compared. European Journal of Cognitive Psychology, 4, 113-139.

Davis, C. L., \& Cooper, S. (2011). Fitness, fatness, cognition, behavior, and academic achievement among overweight children: do cross-sectional associations correspond to exercise trial outcomes? Preventive Medicine, 52, S65-S69.

Donnelly, J. E., \& Lambourne, K. (2011). Classroom-based physical activity, cognition, and academic achievement. Preventive Medicine, 52, S36-S42.

Engelkamp, J., \& Cohen, R. L. (1991). Current issues in memory of action events. Psychological Research, 53, 175-182.

Engelkamp, J., \& Zimmer, H. D. (1984). Motor programme information as a separable memory unit. Psychological Research, 46, 283-299.

Engelkamp, J., \& Zimmer, H. D. (1985). Motor programs and their relation to semantic memory. German Journal of Psychology, 9, 239-254.

Fedewa, A. L., \& Ahn, S. (2011). The effects of physical activity and physical fitness on children's achievement and cognitive outcomes: a meta-analysis. Research Quarterly for Exercise and Sport, $82,521-535$.

Goldin-Meadow, S., Nusbaum, H., Kelly, S. D., \& Wagner, S. (2001). Explaining math: gesturing lightens the load. Psychological Science, 12, 516-522.

Hillman, C. H., Castelli, D. M., \& Buck, S. M. (2005). Aerobic fitness and neurocognitive function in healthy preadolescent children. Medicine and Science in Sports and Exercise, 37, 1967-1974.

Hostetter, A. B. (2011). When do gestures communicate? a meta-analysis. Psychological Bulletin, 137(2), 297315.

Hostetter, A. B., \& Alibali, M. W. (2008). Visible embodiment: gestures as simulated action. Psychonomic Bulletin and Review, 15, 495-514.

Jäger, R., \& Bortz, J. (2001). Rating scales with smilies as symbolic labels - determined and checked by methods of psychophysics. In Annual Meeting of the International Society for Psychophysics.

Kibbe, D. L., Hackett, J., Hurley, M., McFarland, A., Schubert, K. G., Schultz, A., \& Harris, S. (2011). Ten years of take 10 ! : integrating physical activity with academic concepts in elementary school classrooms. Preventive Medicine, 52, S43-S50.

Kim, Y., \& Lee, S. (2009). Physical activity and abdominal obesity in youth. Applied Physiology, Nutrition, and Metabolism, 34, 571-581.

Lindgren, R., \& Johnson-Glenberg, M. (2013). Emboldened by embodiment: six precepts for research on embodied learning and mixed reality. Educational Researcher, 42, 445-452.

Lubans, D. R., Morgan, P. J., \& Tudor-Locke, C. (2009). A systematic review of studies using pedometers to promote physical activity among youth. Preventive Medicine, 48, 307-315.

Mahar, M. T., Murphy, S. K., Rowe, D. A., Golden, J., Shields, A. T., \& Raedeke, T. D. (2006). Effects of a classroom-based program on physical activity and on-task behavior. Medicine and Science in Sports and Exercise, 38, 2086-2094.

Mahar, M. T. (2011). Impact of short bouts of physical activity on attention-to-task in elementary school children. Preventive Medicine, 52, S60-S64.

Paas, F., \& Sweller, J. (2012). An evolutionary upgrade of cognitive load theory: using the human motor system and collaboration to support the learning of complex cognitive tasks. Educational Psychology Review, 24, 27-45. 
Pontifex, M., Hillman, C., Fernhall, B., Thompson, K., \& Valentini, T. (2009). The effect of acute aerobic and resistance exercise on working memory. Medicine and Science in Sports and Exercise, $41,927$.

Pouw, W. T., de Nooijer, J. A., van Gog, T., Zwaan, R. A., \& Paas, F. (2014). Toward a more embedded/extended perspective on the cognitive function of gestures. Frontiers in Psychology, 5.

Pouw, W. T., Van Gog, T., \& Paas, F. (2014). An embedded and embodied cognition review of instructional manipulatives. Educational Psychology Review, 26, 51-72.

Sibley, B. A., \& Etnier, J. L. (2003). The relationship between physical activity and cognition in children: a metaanalysis. Pediatric Exercise Science, 15, 243-256.

Strong, W. B., Malina, R. M., Blimkie, C. J., Daniels, S. R., Dishman, R. K., Gutin, B., Hergenroeder, A., Nixon, P. A., Pivarnik, J. M., Rowland, S., Trost, T., \& Trudeau, F. (2005). Evidence based physical activity for school-age youth. The Journal of Pediatrics, 146, 732-737.

Tomporowski, P. D., Davis, C. L., Miller, P. H., \& Naglieri, J. A. (2008). Exercise and children's intelligence, cognition, and academic achievement. Educational Psychology Review, 20, 111-131.

Wilson, M. (2002). Six views of embodied cognition. Psychonomic Bulletin and Review, 9, 625-636. 